\title{
Controller for Boost Converter in S-domain and Z- Domain by using SISOTOOL MATLAB
}

\author{
Ammar ALgamluoli \\ Assistant Lecturer at University of Baghdad \\ Iraq/ Baghdad
}

\begin{abstract}
Many applications use dc to dc boost converter. For example, laptop chargers, dc Motor drives and any applications that require high dc voltages [1][5]. The benefit of using this circuit is to minimize from using large numbers of batteries. This circuit produces high output dc voltage. Almost this voltage is greater than or equal input voltage that depend on type of application. The aim of this paper is to make controllers for boost converter in S- domain and Z- Domain by using MATLAB SISTOOL. Also, comparison between two controllers are investigated in this paper.
\end{abstract}

\section{Keywords}

Boost Converter, MATLAB SISOTOOL, Controller in SDomain and Z- Domain.

\section{INTRODUCTION}

Nowadays, most applications like renewable energy, hybrid electric car and laptops charger use dc to dc converter like buck, buck boost and boost converter to reduce from battery size. Most company look at to reduce from size especially in aerospace application to reduce from weight. So, the controller is more important in these applications to get high response in output voltage [2][4]. In this paper, two controllers in $\mathrm{S}$ and $\mathrm{Z}$ domain are made for boost converter by using SISOTOOL MATLAB. Circuit diagram of boost converter is shown below in fig (1).

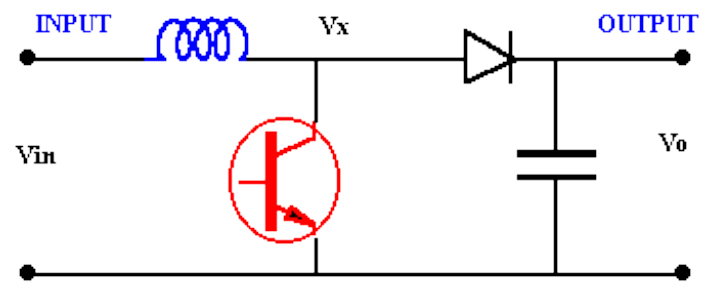

Figure (1) Boost converter Circuit Diagram

The operation of boost converter circuit, when transistor is closed, the circuit will be isolated by this switch because (short circuit). Inductor will charge from supply, and diode will be in reverse direction. So, the output voltage will be capacitor voltage. When transistor is opened, the output voltage will be from supply and inductor[3]. So, that the output voltage is large. In this project, two controllers in $\mathrm{S}$ and $\mathrm{Z}$ will be made for boost converter circuit to get best high response. The boost converter will have the following rated characteristics:

Input voltage: $\mathrm{Vin}=9 \mathrm{~V}$, Output voltage $(\mathrm{Vo})$ in the range between $12 \mathrm{~V}$, Maximum power output $=120 \mathrm{~W}$, Switching frequency $\mathrm{Fs}=100 \mathrm{KHz}$. At first the values of $\mathrm{L}$ and $\mathrm{C}$ assuming a maximum current ripple of $1 \%$ and a maximum voltage ripple of $0.75 \%$. Where $\mathrm{L}$ and $\mathrm{C}$ are shown below after using those two expression.

\author{
Muatafa Falah Mahmood \\ Tech. Eng. College Technical of Electrical \\ Iraq/ Baghdad
}

$$
L=\frac{\operatorname{Vin} * D}{(F * \operatorname{deltal} L)}, C=\frac{(D * V o)}{(R * \text { deltaVo } * F)}
$$

\section{$\mathrm{L}=1.6875 \mathrm{e}-004$}

$\mathrm{C}=2.7778 \mathrm{e}-004$

In order to find transfer function between output voltage and duty cycle for boost converter, state space modelling for boost converter is used for finding transfer function which is shown below.

$$
\frac{v_{o p}(s)}{d_{p}(s)}=\frac{\frac{V_{O}}{(1-D)}\left(1-\frac{s L}{(1-D)^{2} R}\right)}{\frac{s^{2} L C}{(1-D)^{2}}+\frac{s L}{R(1-D)^{2}}+1}
$$

Where D is duty cycle, Vop is output voltage and d p is duty cycle.

After substituting the values in transfer function, it will be:

$$
\begin{gathered}
-0.003 \mathrm{~s}+12 \\
\hline-\mathrm{-} .333 \mathrm{e}-008 \mathrm{~s} \mathrm{~s}^{\wedge} 2+0.00025 \mathrm{~s}+1
\end{gathered}
$$

After rearrange the transfer function in order to find poles, zeros and gain, it will be as shown below:

36000 (s-4000)

\section{$\left(\mathrm{S}^{\wedge} 2+3000 \mathrm{~s}+1.2 \mathrm{e} 007\right)$}

The transfer function has zero in right half plane. So, the plant is unstable see fig (2). In order to make this system work in best performance and very fast with less over shoot. This system requires controller to meet design specification. The root locus of the system as shown below:

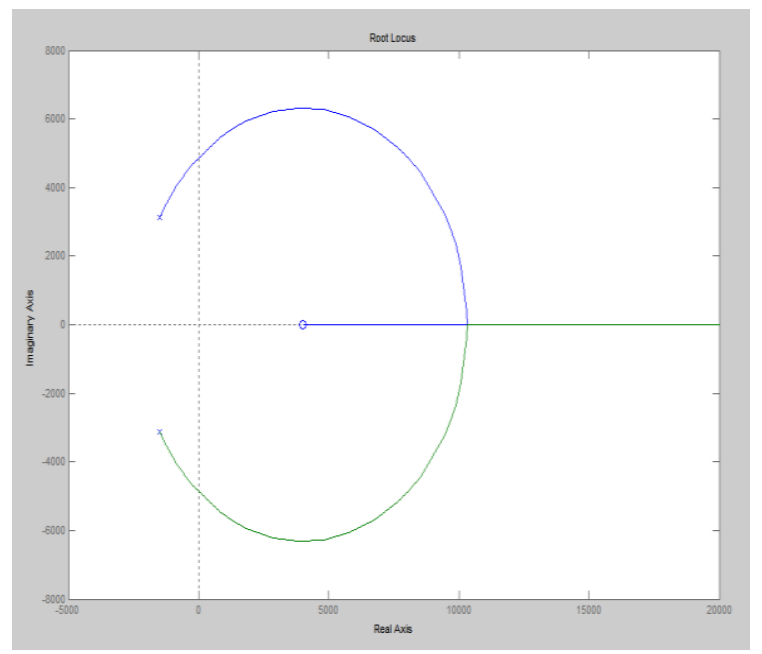

Figure 2 the root locus of the plant in $\mathrm{S}$ domain 


\section{METHODOLOGY}

The boost converter is used in this project in order to find best controller by using SISOTOOL MATLAB. The controller is found in $\mathrm{S}$ domain and $\mathrm{Z}$ domain. The comparison is made for two controllers.

\subsection{System Implementation in S domain}

After getting transfer function of the system, the transfer function in $\mathrm{S}$ domain is:

$-36000(\mathrm{~s}-4000)$

$$
\left(\mathrm{S}^{\wedge} 2+3000 \mathrm{~s}+1.2 \mathrm{e} 007\right)
$$

Now, the system is unstable because it has zero in right half plane. It requires controller to get best performance. This controller will be built by SISOTOOL MATLAB see Fig (4) simulation of the system. After using SISOTOOL, the controller (C) will be:

$$
6.65\left(\mathrm{~s}^{\wedge} 2+3000 \mathrm{~s}+1.2 \mathrm{e} 007\right)
$$

$$
\mathrm{s}(\mathrm{s}+2.9 \mathrm{e} 005)
$$

The poles, zeros and gain of the controller are $(2.9 \mathrm{e} 005,0)$, ($1500-3122.5 i,-1500+3122.5 i)$ and 6.65 respectively. This controller has complex zero to cancel complex pole in plant. It has real far pole, and one integrator to get zero steady state error. The design requirements are given (damping factor $=0.707$, natural freq. $=2 * p^{*} * 5000$ ). After using SISOTOOL manger is to choose the best controller for the system. The root locus of the system with controller see Fig (3):

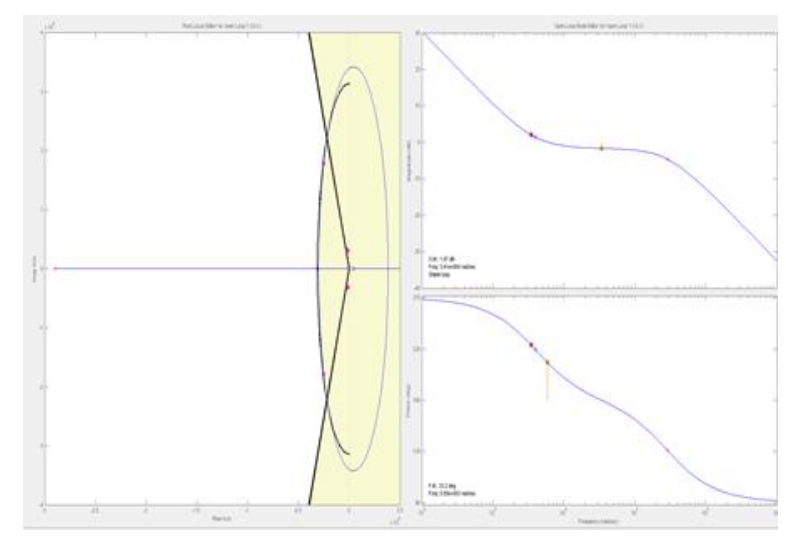

Figure 3 Root locus of the system with controller after using SISOTOOL MATLAB

As above, the controller is found, is good for the system because it met the design requirements.

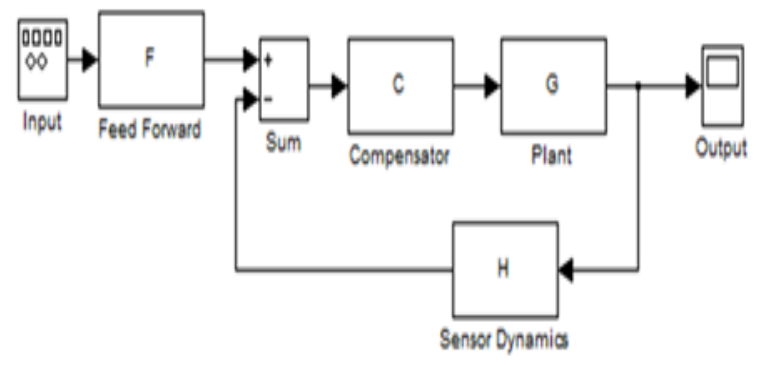

Figure 4 simulation of the plant with controller

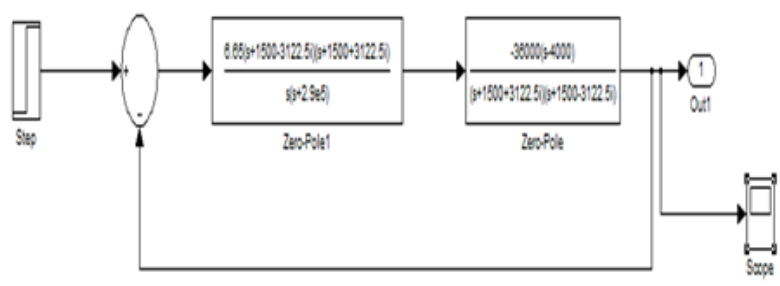

Figure (5) System Simulation with controller

Above system simulation with controller after using SISOTTOL MATLAB see fig (5) in order to find best performance of the system.

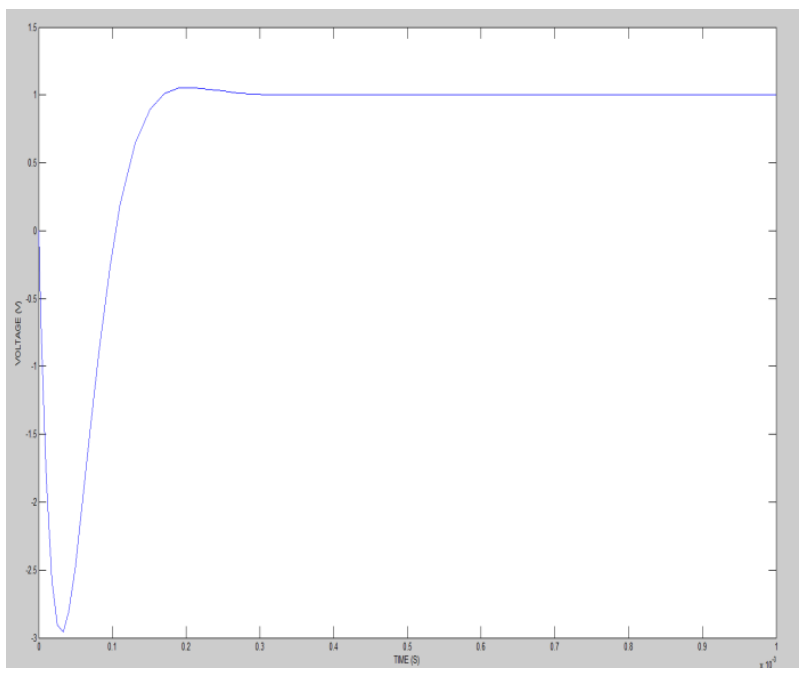

Fig (5.1) Response of the system

The response of the closed loop system is shown above in fig (5.1). The system is stable and fast and the percentage overshoot is $4.6 \%$, rise time $=4.5 \mathrm{e}-5$ and settling time $=0.00015 \mathrm{~s}$. However, there is huge under shoot in this system because the transfer function of the plant has zero in right half plane.

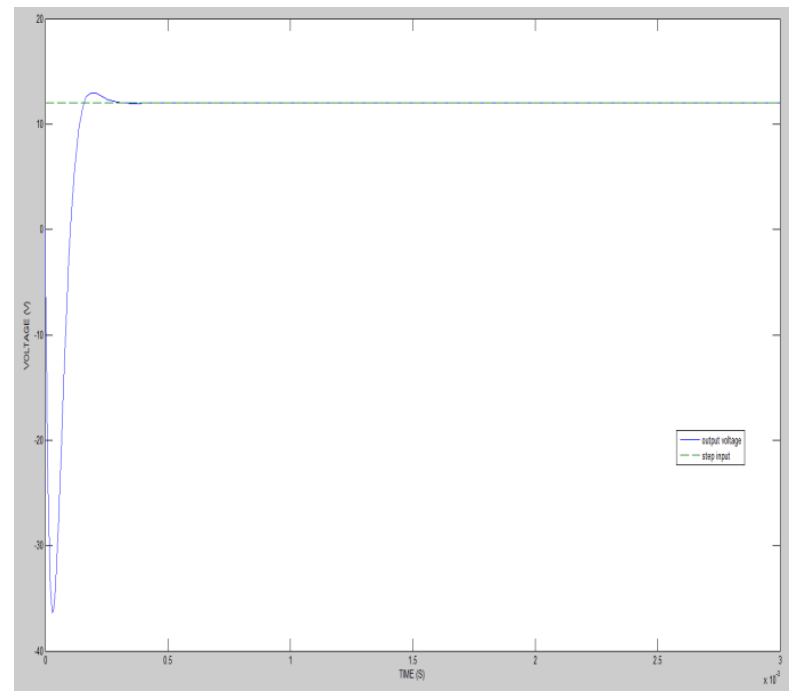

Fig (4.4) Response of the system with 12 input step function

As shown above, there is huge under shoot because of the zero in right half plane. For minimizing this case is to use saturation block in simulation to reduce that undershoot. The simulation circuit and response of the closed loop system are 
shown below in fig (5.2) and fig (5.3):

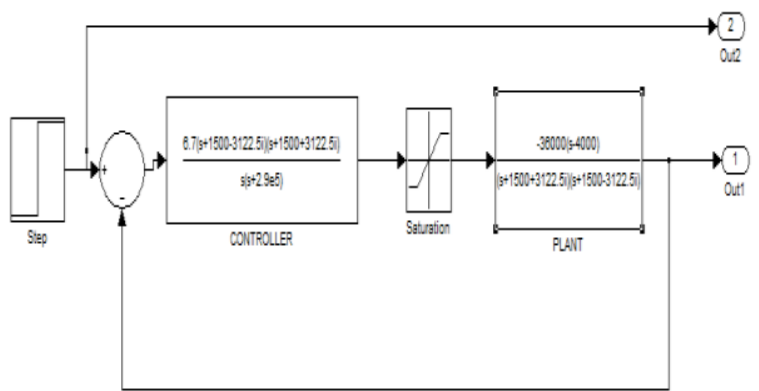

Fig (J.2) Simulation circuit witn saturation piock

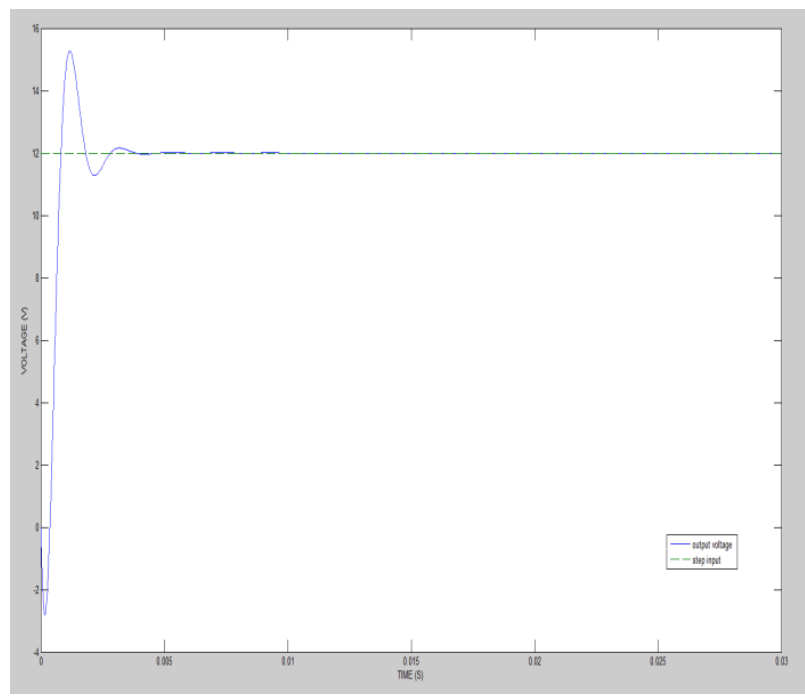

Fig (5.3) response of the system with saturation and step input $=12$

\subsection{System Implementation in z Domain}

The transfer function of the system in $\mathrm{S}$ domain is shown below:

$$
\begin{aligned}
& -36000(\mathrm{~s}-4000) \\
& -\left(\mathrm{S}^{\wedge} 2+3000 \mathrm{~s}+1.2 \mathrm{e} 007\right)
\end{aligned}
$$

The transfer function of the system in $\mathrm{z}$ domain is shown below by using this command [ $\mathrm{sysd}=\mathrm{c} 2 \mathrm{~d}(\mathrm{tf}, \mathrm{T})]$ in MATLAB.

Where $\mathrm{T}=$ sampling time.

Sysd $=$ transfer function in $\mathrm{z}$ domain .

Then, the transfer function in $\mathrm{z}$ domain will be:

\section{$-0.34745(z-1.041)$}

\section{$\left(Z^{\wedge} 2-1.969 z+0.9704\right)$}

Sampling time: 1e-005

The poles, zeros and gain of the TF are $(0.9846+0.0308 \mathrm{i}$, $0.9846-0.0308 i),(1.041)$ and $(-0.34745)$ respectively. The design specifications are (the sampling frequency is 100000 HZ. So, the T will equal 1e-005).

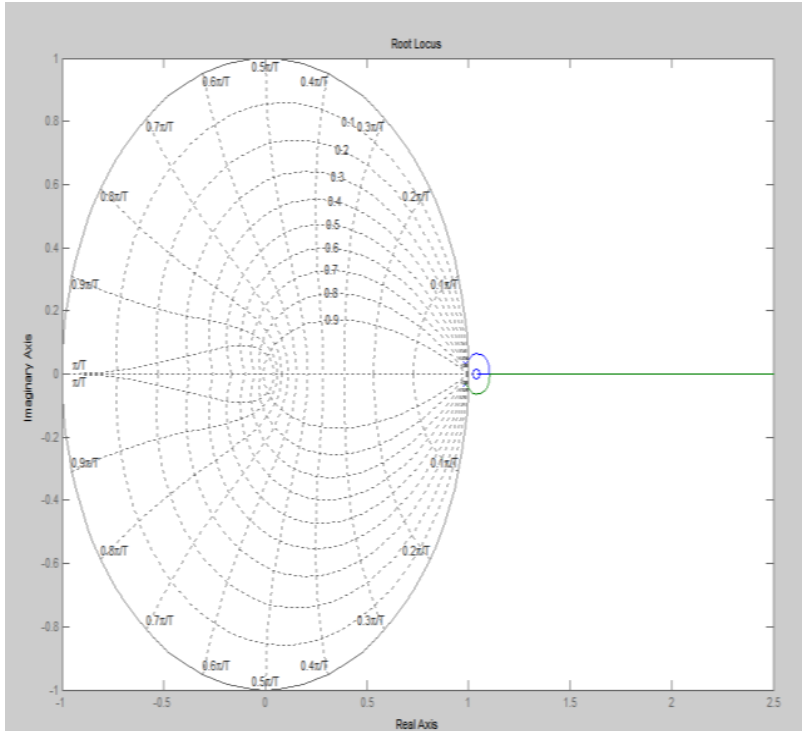

Fig (6) root locus of the plant

This system is unstable. It has zero outside the circle. So, it requires controller to work in best performance. The best controller for this system is to meet the design requirement as shown below:

damping factor $=0.7$;

$\omega_{0}=2 * \pi * 5000 \mathrm{rad} / \mathrm{s}$

$\omega_{s}=2 * \pi * F_{s} \mathrm{rad} / \mathrm{s}$

$\frac{\omega_{s}}{\omega_{0}}=20$

After using SISOTOOL in MATLAB is to build the controller of the system, and to check the response of the system. The root louse of the system with controller is shown below:

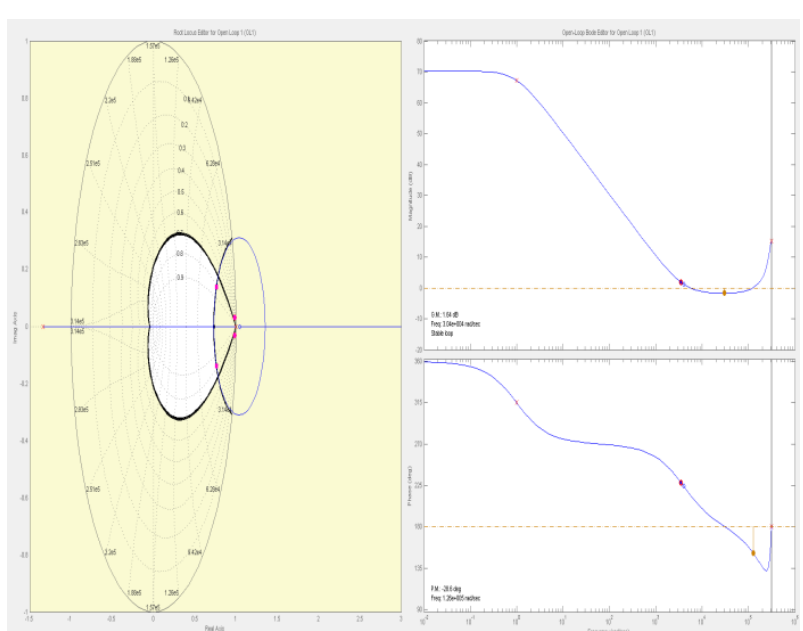

Figure (6.1) root locus of the system with controller after using SISOTOOL MATLAB

Then, the controller of the system will be:

$5.3481\left(z^{\wedge} 2-1.969 z+0.9704\right)$

$$
(\mathrm{z}-1)(\mathrm{z}+1.335)
$$

Sampling time: 1e-005

This controller has complex zero to cancel complex pole in the plant. It has real pole outside the circle, and one integrator is to get zero steady state error. 


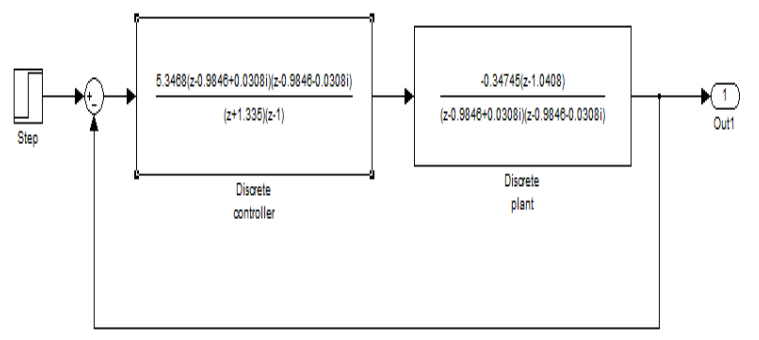

Fig (6.2) system Simulation with feedback control

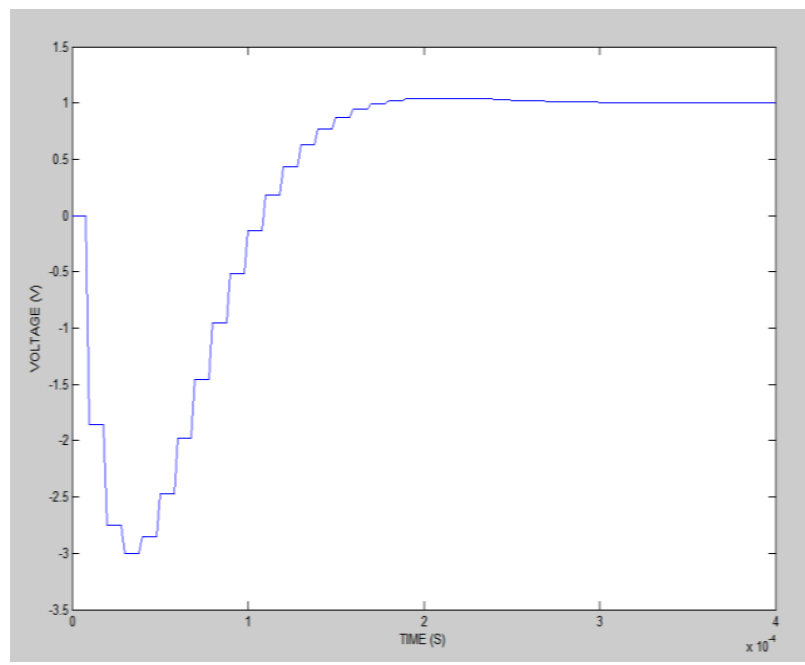

Fig (6.3) response of the system with step input =1

As above, it can be seen that the system is stable and it meets design specification. It is fast with overshoot $4.58 \%$, at settling time $=0.00015 \mathrm{~S}$ and rise time $=4.6 \mathrm{e}-005 \mathrm{~s}$.

\section{COMPARISON BETWEEN TWO CONTROLLERS}

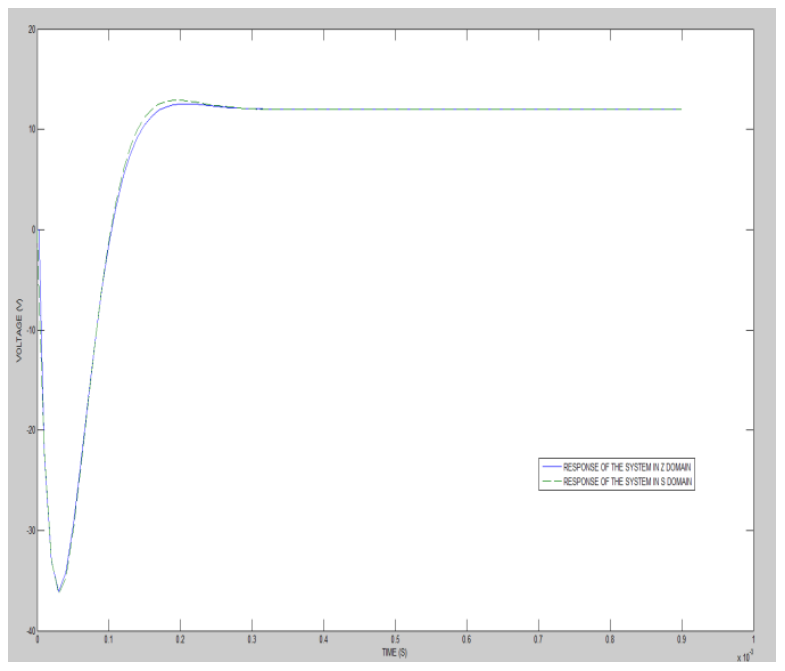

Figure (7) the response of the system in $S$ and $Z$ domain

From the figure above shows that the response of the system in two domains are similar. However, it has huge undershoot because the transfer function has one unstable zero.

\section{SIMULATION OF BOOST CONVERTER CIRCUIT WITH CONTROLLER}

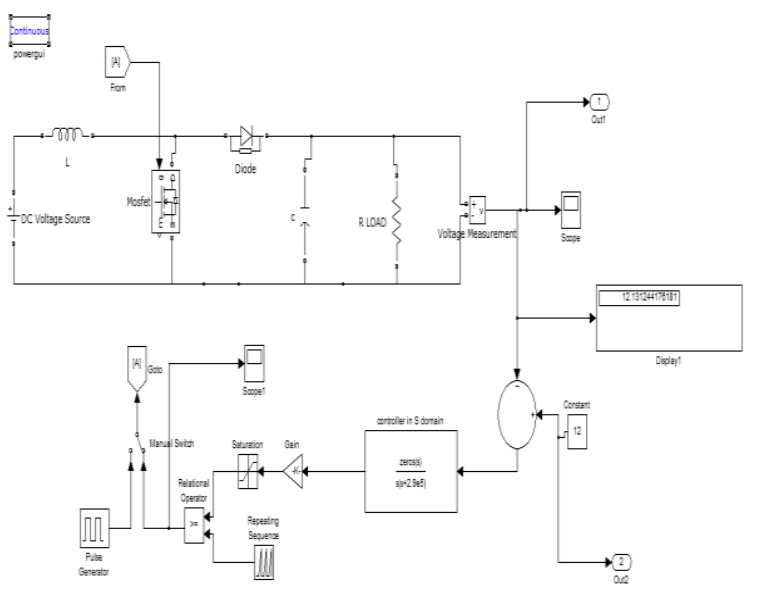

Figure (x) boost converter circuit witn controner in s domain

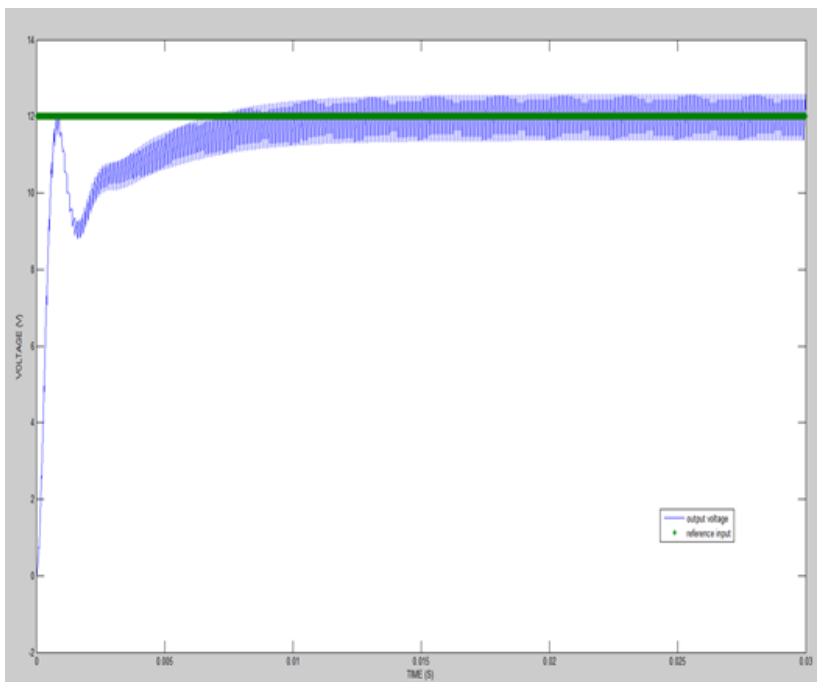

Fig (8.1) Output voltage of the system

\section{CONCLUSION}

In conclusion, it can be seen that the transfer function of the system has the zero in right half plane. This zero has made the system unstable. The controller of the system has been made by using SISOTOOL MATLAB in $\mathrm{S}$ domain and $\mathrm{Z}$ domain to make system work in best performance. It has made the system too fast and, it has met the design requirements. The comparison between two controllers have been done in this project.

\section{REFERENCES}

[1] Dinca, L., \& Corcau, J. I. (2016, June). PI versus fuzzy control for a DC to DC boost converter. In Power Electronics, Electrical Drives, Automation and Motion (SPEEDAM), 2016 International Symposium on (pp. 803-808). IEEE.

[2] Solaiman, H. M., Hasan, M. M., Mohammad, A., Kawsar, S. R., \& Hassan, M. A. (2015, March). Performance analysis of DC to DC boost converter using different control methods. In Electrical, Computer and Communication Technologies (ICECCT), 2015 IEEE 
International Journal of Computer Applications (0975 - 8887)

Volume 174 - No.9, September 2017

International Conference on (pp. 1-5). IEEE.

[3] Veerachary, M. (2012, August). Digital controller design for fourth-order soft-switching boost converter. In Industrial and Information Systems (ICIIS), 2012 7th IEEE International Conference on (pp. 1-5). IEEE.

[4] Erisman, B. P. (1995). U.S. Patent No. 5,402,060.
Washington, DC: U.S. Patent and Trademark Office.

[5] Gow, J. A., \& Manning, C. D. (2000). Controller arrangement for boost converter systems sourced from solar photovoltaic arrays or other maximum power sources. IEE Proceedings-Electric Power Applications, 147(1), 15-20. 